\title{
Anionic Ring-Opening Copolymerization of L-Lactide with a Five-Membered Cyclic Carbonate Having a Glucopyranoside Structure
}

\author{
By Osamu HABA, ${ }^{*}$ Nanako FURUICHI, and Yosuke AKASHIKA
}

The anionic ring-opening copolymerization of L-lactide (LL) with a five-membered cyclic carbonate having the glucopyranoside structure, methyl 4,6- $O$-benzilidene-2,3- $O$-carbonyl- $\alpha$-D-glucopyranoside (MBCG), was carried out using potassium tert-butoxide $\left(t\right.$-BuOK) as the initiator and tetrahydrofuran $(\mathrm{THF})$ as the solvent at $30^{\circ} \mathrm{C}$ for $12 \mathrm{~h}$. The mole fractions of LL in the copolymer $\left(f_{\mathrm{LL}}\right)$ of all copolymers were nearly equal to the corresponding mole fraction of LL in the feed $\left(F_{\mathrm{LL}}\right)$. Deprotection of the copolymer was performed using trifluoroacetic acid in dichloromethane. ${ }^{1} \mathrm{H}$ NMR spectra of the resulting product indicated that deprotection was completely achieved due to the absence of the aromatic proton signals. KEY WORDS: Copolymerization / Ring-Opening Polymerization / Biodegradable / Sugar / Glucose /

Poly(L-lactic acid) (PLLA), which is generally prepared by the ring-opening polymerization of L-lactide (LL), has been used in a wide range of applications, such as biomedical materials, beased on its biodegradable, biocompatible, lowtoxic, and renewable properties. In order to improve its physical properties or bio-functionalities, the copolymers of L-lactide with other monomeric units, such as ethers, ${ }^{1-5}$ esters, ${ }^{6-9}$ amides, ${ }^{4,10}$ carbonates, ${ }^{11-15}$ etc., have been prepared.

We have reported the ring-opening polymerization of a fivemembered cyclic carbonate, methyl 4,6- $O$-benzylidene-2,3- $O$ carbonyl- $\alpha$,D-glucopyranoside (MBCG), which was prepared from methyl $\alpha$-D-glucopyranoside. ${ }^{16}$ It is well known that such five-membered cyclic carbonates are not suitable as the monomers in the ring-opening polymerization because a considerable amount of carbon dioxide eliminates during the polymerization that produces the polyether product. ${ }^{17-20} \mathrm{How}-$ ever, we have found that the anionic ring-opening polymerization of MBCG smoothly proceeds without the elimination of carbon dioxide to give the polycarbonate containing no polyether repeating units. Thus, MBCG is a rare fivemembered cyclic carbonate having the ring-opening polymerization capability, and therefore, it is interesting to investigate its copolymerization behavior with other cyclic monomers.

In this study, we carried out the anionic ring-opening copolymerization of LL with MBCG. The resulting product was converted to hydroxyl-bearing copolymers by removing the benzylidene protecting groups (Scheme 1). That should be expected to add some functionalities to PLLA, such as hydrophilicity and reactivity.

\section{EXPERIMENTAL}

\section{Measurements}

The infrared (IR) spectra were recorded using a HORIBA FT-210 spectrometer. The ${ }^{1} \mathrm{H}$ and ${ }^{13} \mathrm{C}$ NMR spectra were
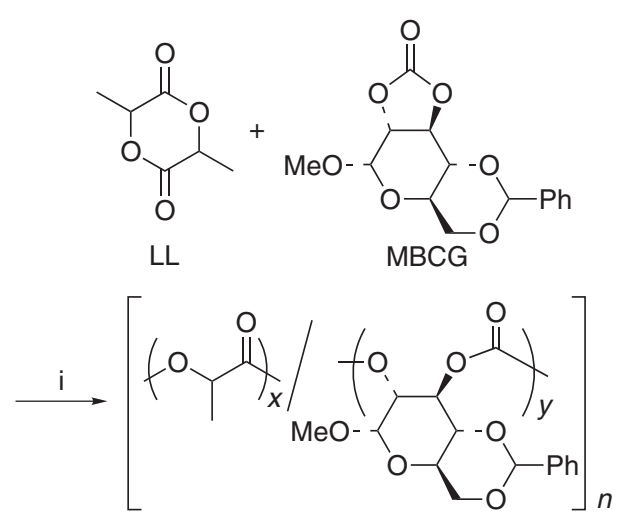

Poly(LL-Co-MBCG)

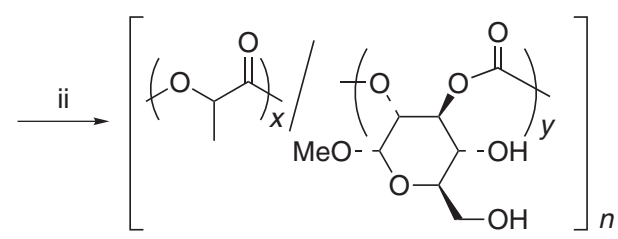

Poly(LL-co-MCG)

Scheme 1. Copolymerization of LL with MBCG and acid-catalyzed deprotection. Conditions: i) $t$-BuOK, THF, $30^{\circ} \mathrm{C}$, ii) $\mathrm{CF}_{3} \mathrm{COOH}, \mathrm{H}_{2} \mathrm{O}$ $\mathrm{CH}_{2} \mathrm{Cl}_{2}, 25^{\circ} \mathrm{C}$.

measured in $\mathrm{CDCl}_{3}$ by a JEOL JNM-ECX $400(400 \mathrm{MHz}$ for ${ }^{1} \mathrm{H}$ and $100 \mathrm{MHz}$ for ${ }^{13} \mathrm{C}$ ) spectrometer at room temperature. The chemical shift values were in ppm downfield from tetramethylsilane $(0.0 \mathrm{ppm})$ and $\mathrm{CDCl}_{3}(77.0 \mathrm{ppm})$ used as the internal standards for the ${ }^{1} \mathrm{H}$ and ${ }^{13} \mathrm{C}$ measurements, respectively. The number-average $\left(M_{\mathrm{n}}\right)$ and weight-average $\left(M_{\mathrm{w}}\right)$ molecular weights were estimated by size-exclusion chromatography (SEC) using a Tosoh DP-8020 pump, a Viscotek TDA MODEL-300 refractive index (RI) detector and polystyrene gel columns (Tosoh TSK gels $\mathrm{G} 2500 \mathrm{H}$, $\mathrm{G} 3000 \mathrm{H}, \mathrm{G} 4000 \mathrm{H}$ and $\mathrm{GMH}$ ) in DMF containing $1 \mathrm{wt} \% \mathrm{LiBr}$ 
using a calibration curve of polystyrene standards. The thermal gravimetric analyses (TGA) and differential scanning calorimetry (DSC) results were recorded by a Seiko SSC/5200 (DSC 220) instrument at the heating/cooling rate of $10^{\circ} \mathrm{C} / \mathrm{min}$ under a nitrogen atmosphere.

\section{Materials}

Tetrahydrofuran (THF, Kanto Chemicals) was refluxed over sodium-benzophenone ketyl and distilled just before use. Potassium tert-butoxide $(t$-BuOK) was purchased as a $1.0 \mathrm{M}$ solution in THF (Aldrich) and used as received. Methyl 4,6$O$-benzylidene- $\alpha$-D-glucopyranoside $(\mathbf{1})^{21}$ and methyl 2,3-Ocarbonyl-4,6- $O$-benzylidene- $\alpha$-D-glucopyranoside $\quad(\mathrm{MBCG})^{22}$ were prepared according to the literature. A commercial Llactide (LL) (Kanto Chemicals) was recrystalized from ethyl acetate and sublimed in vacuo just before use. Trifluoroacetic acid (Kanto Chemicals), methyl chloroformate (Wako Chemicals), acetyl chloride (Kanto Chemicals), and all other chemicals were commercially available and used as received.

\section{Copolymerization of L-Lactide with MBCG}

A typical procedure was as follows: In a test tube equipped with a 3-way stopcock and filled with nitrogen, LL $(0.19 \mathrm{~g}$, $1.3 \mathrm{mmol})$ and MBCG $(0.41 \mathrm{~g}, 1.3 \mathrm{mmol})$ were dissolved in THF $\left(0.8 \mathrm{~mL}, 3.0 \mathrm{~mol} \cdot \mathrm{L}^{-1}\right)$. The solution was heated to $30^{\circ} \mathrm{C}$, then an initiator, $t$-BuOK $(1.0 \mathrm{M}$ solution in THF, $0.10 \mathrm{~mL}$, $0.10 \mathrm{mmol}$ ) was added via a syringe. The solution was stirred at this temperature for $12 \mathrm{~h}$. Acetic acid $(12 \mu \mathrm{L})$ was added to quench the reaction, and the solution was poured into ice-cold methanol $(50 \mathrm{~mL})$. The white precipitate was collected by filtration, reprecipitated from $\mathrm{CHCl}_{3}$-methanol and dried in vacuo at room temperature. Yield $0.49 \mathrm{~g}(83 \%) . M_{\mathrm{n}}=$ 5,100 (SEC). The LL content in the obtained copolymer was estimated using the ${ }^{1} \mathrm{H}$ NMR spectrum by comparing the peak area ratios of the methyl proton around $1.2 \mathrm{ppm}$ and the aromatic proton around $7 \mathrm{ppm}$.

\section{Deprotection from the Copolymer}

A typical procedure was as follows: In a $10 \mathrm{~mL}$ flask, the copolymer $\left(0.21 \mathrm{~g}, f_{\mathrm{LL}}=0.48\right)$ was dissolved in dichloromethane $(2.0 \mathrm{~mL})$. To this solution was added a $90 \%$ aqueous trifluoroacetic acid solution $(0.11 \mathrm{~mL})$. After the solution was stirred for $1 \mathrm{~h}$ at room temperature, the resulting polymeric product was poured into diethyl ether $(50 \mathrm{~mL})$. The precipitated polymer was separated by filtration and dried in vacuo at room temperature to a constant weight. Yield $0.17 \mathrm{~g}(99 \%) \cdot M_{\mathrm{n}}=$ 8,700 (SEC).

\section{Model Compounds}

Methyl 2- $O$-acetyl-4,6- $O$-benzylidene- $\alpha$-D-glucopyranoside (2a) and Methyl 3-O-acetyl-4,6- $O$-benzylidene- $\alpha$-D-glucopyranoside (2b). To a solution of methyl 4,6- $O$-benzylidene- $\alpha$-D-glucopyranoside $(5.6 \mathrm{~g}, 20 \mathrm{mmol})$ and triethylamine $(2.2 \mathrm{~g}, 22 \mathrm{mmol})$ in THF $(20 \mathrm{~mL})$, acetyl chloride $(2.3 \mathrm{~g}, 23 \mathrm{nnol})$ was dropwise added at $0{ }^{\circ} \mathrm{C}$. The mixture was then stirred overnight at room temperature. The resulting yellow solution was poured into ice- water and the precipitate was collected by filtration. The crude material was purified by column chromatography on silica gel (24 g) with ethyl acetate/ $n$-hexane $(1 / 2, \mathrm{v} / \mathrm{v})$. Compounds $2 \mathbf{a}$ and $\mathbf{2 b}$ were obtained as fractions at $R_{f}=0.23$ and 0.04 , respectively.

2a: Yield, $2.3 \mathrm{~g} \quad(7.1 \mathrm{mmol}, 35 \%) .{ }^{1} \mathrm{H} \mathrm{NMR}\left(\mathrm{CDCl}_{3}\right.$, $400 \mathrm{MHz}): \delta(\mathrm{ppm})=7.50-7.49(\mathrm{~m}, 2 \mathrm{H}, \mathrm{Ar}), 7.39-7.38(\mathrm{~m}$, $3 \mathrm{H}, \mathrm{Ar}), 5.56(\mathrm{~s}, 1 \mathrm{H}, \mathrm{PhCH}), 4.96\left(\mathrm{~d},{ }^{3} J_{1-2}=4.1,1 \mathrm{H}, \mathrm{H}-1\right)$, $4.79\left(\mathrm{dd},{ }^{3} J_{2-1}=3.7,{ }^{3} J_{2-3}=9.9, \quad 1 \mathrm{H}, \quad \mathrm{H}-2\right), 4.30 \quad(\mathrm{dd}$, $\left.{ }^{3} J_{6 \mathrm{eq}-5}=4.6,{ }^{2} J_{6 \mathrm{eq}-6 \mathrm{ax}}=10.1,1 \mathrm{H}, \mathrm{H}-6 \mathrm{eq}\right), 4.19\left(\mathrm{t},{ }^{3} J_{3-2}=\right.$ $\left.{ }^{3} J_{3-4}=9.6,1 \mathrm{H}, \mathrm{H}-3\right), 3.86\left(\mathrm{dt},{ }^{3} J_{5-4}={ }^{3} J_{5-6 \mathrm{ax}}=4.6,{ }^{3} J_{5-6 \mathrm{eq}}=\right.$ $9.4,1 \mathrm{H}-\mathrm{H}-5), 3.77\left(\mathrm{t},{ }^{3} J_{6 \mathrm{ax}-5}={ }^{2} J_{6 \mathrm{ax}-6 \mathrm{eq}}=10.1,1 \mathrm{H}, \mathrm{H}-6 \mathrm{ax}\right)$, $3.57\left(\mathrm{t},{ }^{3} J_{4-3}={ }^{3} J_{4-5}=9.16,1 \mathrm{H}, \mathrm{H}-4\right), 3.41\left(\mathrm{~s}, 3 \mathrm{H}, \mathrm{OCH}_{3}\right)$, 2.47 (s, 1H, C(3)-OH), $2.17\left(\mathrm{~s}, 3 \mathrm{H},-\mathrm{CH}_{3}\right) .{ }^{13} \mathrm{C} \mathrm{NMR}\left(\mathrm{CDCl}_{3}\right.$, $100 \mathrm{MHz}): \delta(\mathrm{ppm})=170.8\left(\mathrm{CH}_{3} \mathrm{C}=\mathrm{O}\right), 136.9,129.3,128.3$, 126.2 (Ar), $102.0(\mathrm{PhCH}), 97.4(\mathrm{C}-1), 81.3(\mathrm{C}-4), 73.5(\mathrm{C}-2)$, 68.8 (C-6), 68.5 (C-3), $61.9(\mathrm{C}-5), 55.3\left(\mathrm{OCH}_{3}\right), 20.9\left(-\mathrm{CH}_{3}\right)$.

2b: Yield $0.64 \mathrm{~g} \quad(2.0 \mathrm{mmol}, 10 \%)$. ${ }^{1} \mathrm{H} \mathrm{NMR}\left(\mathrm{CDCl}_{3}\right.$, $400 \mathrm{MHz}): \delta(\mathrm{ppm})=7.45-7.44(\mathrm{~m}, 2 \mathrm{H}, \mathrm{Ar}), 7.36-7.35(\mathrm{~m}$, $3 \mathrm{H}, \mathrm{Ar}), 5.49(\mathrm{~s}, 1 \mathrm{H}, \mathrm{PhCH}), 5.32\left(\mathrm{dd},{ }^{3} J_{2-1}=3.7,{ }^{3} J_{2-3}=9.9\right.$, $1 \mathrm{H}, \mathrm{H}-2), 4.80\left(\mathrm{~d},{ }^{3} J_{1-2}=4.1,1 \mathrm{H}, \mathrm{H}-1\right), 4.30\left(\mathrm{dd},{ }^{3} J_{6 \mathrm{eq}-5}=\right.$ $\left.4.6,{ }^{2} J_{6 \mathrm{eq}-6 \mathrm{ax}}=10.1,1 \mathrm{H}, \mathrm{H}-6 \mathrm{eq}\right), 3.86\left(\mathrm{dt},{ }^{3} J_{5-4}={ }^{3} J_{5-6 \mathrm{ax}}=\right.$ $\left.5.0,{ }^{3} J_{5-6 \mathrm{eq}}=9.6,1 \mathrm{H}-\mathrm{H}-5\right), 3.74\left(\mathrm{t},{ }^{3} J_{6 \mathrm{ax}-5}={ }^{2} J_{6 \mathrm{ax}-6 \mathrm{eq}}=10.1\right.$, $1 \mathrm{H}, \mathrm{H}-6 \mathrm{ax}), 3.66\left(\mathrm{t},{ }^{3} J_{3-2}={ }^{3} J_{3-4}=3.6,1 \mathrm{H}, \mathrm{H}-3\right), 3.55(\mathrm{t}$, $\left.{ }^{3} J_{4-3}={ }^{3} J_{4-5}=10.1,1 \mathrm{H}, \mathrm{H}-4\right), 3.46\left(\mathrm{~s}, 3 \mathrm{H}, \mathrm{OCH}_{3}\right), 2.25(\mathrm{~s}$, $1 \mathrm{H}, \mathrm{C}(2)-\mathrm{OH}), 2.12\left(\mathrm{~s}, 3 \mathrm{H},-\mathrm{CH}_{3}\right),{ }^{13} \mathrm{C} \mathrm{NMR} \quad\left(\mathrm{CDCl}_{3}\right.$, $100 \mathrm{MHz}): \delta(\mathrm{ppm})=171.1\left(\mathrm{CH}_{3} \mathrm{C}=\mathrm{O}\right), 137.0,129.1,128.2$, 126.1 (Ar), $101.5(\mathrm{PhCH}), 100.0(\mathrm{C}-1), 78.6(\mathrm{C}-4), 72.2(\mathrm{C}-2)$, 71.8 (C-3), 68.9 (C-6), $62.7(\mathrm{C}-5), 55.5\left(\mathrm{OCH}_{3}\right), 21.0\left(-\mathrm{CH}_{3}\right)$. Methyl 2- $O$-acetyl-4,6- $O$-benzylidene-3- $O$-methoxycarbonyl- $\alpha$ D-glucopyranoside (3a). To a solution of $\mathbf{2 a}(1.5 \mathrm{~g}, 4.6 \mathrm{mmol})$ and pyridine $(0.36 \mathrm{~mL}, 5.4 \mathrm{mmol})$ in THF $(4.5 \mathrm{~mL})$, methyl chloroformate $(0.41 \mathrm{~mL}, 5.4 \mathrm{mmol})$ was dropwise added at $0{ }^{\circ} \mathrm{C}$. The mixture was then stirred overnight at room temperature. The resulting yellow solution was poured into crushed ice $(50 \mathrm{~g})$ containing concentrated hydrochloric acid $(1 \mathrm{~mL})$, extracted with $\mathrm{CHCl}_{3}$ and washed with water. The organic layer was dried over $\mathrm{MgSO}_{4}$, and concentrated under reduced pressure. The resulting brown oil was purified by column chromatography on silica gel with ethyl acetate/n-hexane $(1 / 2$, $\mathrm{v} / \mathrm{v})$ to give 3a as a colorless viscous oil $(0.46 \mathrm{~g}, 1.2 \mathrm{mmol}$, 26\%). ${ }^{1} \mathrm{H}$ NMR $\left(400 \mathrm{MHz}, \mathrm{CDCl}_{3}\right): \delta(\mathrm{pm})=7.45-7.44(\mathrm{~m}$, 2H, Ar), 7.36-7.34 (m, 3H, Ar), $5.50(\mathrm{~s}, 1 \mathrm{H}, \mathrm{PhCH}), 5.38(\mathrm{t}$, $\left.{ }^{3} J_{3-2}={ }^{3} J_{3-4}=10.0,1 \mathrm{H}, \mathrm{H}-3\right), 4.98\left(\mathrm{~d},{ }^{3} J_{1-2}=3.6,1 \mathrm{H}, \mathrm{H}-1\right)$, $4.90\left(\mathrm{dd},{ }^{3} J_{2-1}={ }^{3} J_{2-3}=4.1,1 \mathrm{H}, \mathrm{H}-2\right), 4.29\left(\mathrm{dt},{ }^{3} J_{5-4}=\right.$ $\left.{ }^{3} J_{5-6 \mathrm{ax}}=5.0,{ }^{3} J_{5-6 \mathrm{eq}}=10.2,1 \mathrm{H}-\mathrm{H}-5\right), 3.91\left(\mathrm{dd},{ }^{3} J_{6 \mathrm{eq}-5}=4.5\right.$, $\left.{ }^{2} J_{6 \mathrm{eq}-6 \mathrm{ax}}=9.7,1 \mathrm{H}, \mathrm{H}-6 \mathrm{eq}\right), 3.74\left(\mathrm{t},{ }^{3} J_{6 \mathrm{ax}-5}={ }^{2} J_{6 \mathrm{ax}-6 \mathrm{eq}}=10.4\right.$, $1 \mathrm{H}, \quad \mathrm{H}-6 \mathrm{ax}), 3.74\left(\mathrm{~s}, 3 \mathrm{H}, \quad \mathrm{COOCH}_{3}\right), 3.69\left(\mathrm{t},{ }^{3} J_{4-3}=\right.$ $\left.{ }^{3} J_{4-5}=9.5,1 \mathrm{H}, \mathrm{H}-4\right), 3.41\left(\mathrm{~s}, 3 \mathrm{H}, \mathrm{OCH}_{3}\right), 2.10(\mathrm{~s}, 3 \mathrm{H}$, $\left.-\mathrm{CH}_{3}\right) . \quad{ }^{13} \mathrm{C} \mathrm{NMR} \quad\left(\mathrm{CDCl}_{3}, \quad 100 \mathrm{MHz}\right): \quad \delta \quad(\mathrm{ppm})=170.4$ $\left(\mathrm{CH}_{3} \mathrm{C}=\mathrm{O}\right), 155.0 \quad(\mathrm{EtOC}=\mathrm{O}), 140.0,129.2,128.3,126.3$ (Ar), 101.7 (PhCH), 97.6 (C-1), 79.2 (C-4), 73.3 (C-3), 71.7 $(\mathrm{C}-2), 68.9(\mathrm{C}-5), 62.3(\mathrm{C}-6), 55.5\left(\mathrm{OCH}_{3}\right), 55.2\left(\mathrm{OCOOCH}_{3}\right)$, $20.9\left(-\mathrm{CH}_{3}\right)$.

Methyl 3- $O$-acetyl-4,6- $O$-benzylidene-2- $O$-methoxycarbonyl- $\alpha$ D-glucopyranoside (3b). This compound was prepared from 
2b $(0.27 \mathrm{~g}, 0.83 \mathrm{mmol})$ by a procedure similar to that for $\mathbf{3 a}$. Yield $0.067 \mathrm{~g}(0.17 \mathrm{mmol}, 21 \%)$. ${ }^{1} \mathrm{H} \mathrm{NMR}\left(400 \mathrm{MHz}, \mathrm{CDCl}_{3}\right)$ : $\delta(\mathrm{ppm})=7.43-7.42(\mathrm{~m}, 2 \mathrm{H}, \mathrm{Ar}), 7.34-7.33$ (m, 3H, Ar), 5.60 $\left(\mathrm{t},{ }^{3} J_{2-1}={ }^{3} J_{2-3}=10.1,1 \mathrm{H}, \mathrm{H}-2\right), 5.49(\mathrm{~s}, 1 \mathrm{H}, \mathrm{PhCH}), 5.01(\mathrm{~d}$, $\left.{ }^{3} J_{1-2}=3.7,1 \mathrm{H}, \mathrm{H}-1\right), 4.76\left(\mathrm{t},{ }^{3} J_{3-2}={ }^{3} J_{3-4}=3.7,1 \mathrm{H}, \mathrm{H}-3\right)$, $4.30\left(\mathrm{dd},{ }^{3} J_{6 \mathrm{eq}-5}=4.6,{ }^{2} J_{6 \mathrm{eq}-6 \mathrm{ax}}=10.1,1 \mathrm{H}, \mathrm{H}-6 \mathrm{eq}\right), 3.93(\mathrm{dt}$, $\left.{ }^{3} J_{5-4}={ }^{3} J_{5-6 \mathrm{ax}}=5.0, \quad{ }^{3} J_{5-6 \mathrm{eq}}=9.9, \quad 1 \mathrm{H}-\mathrm{H}-5\right), 3.79 \quad(\mathrm{~s}, 3 \mathrm{H}$, $\left.\mathrm{COOCH}_{3}\right), 3.76\left(\mathrm{t},{ }^{3} J_{6 \mathrm{ax}-5}={ }^{2} J_{6 \mathrm{ax}-6 \mathrm{eq}}=10.5,1 \mathrm{H}, \mathrm{H}-6 \mathrm{ax}\right)$, $3.63\left(\mathrm{t},{ }^{3} J_{4-3}={ }^{3} J_{4-5}=9.6,1 \mathrm{H}, \mathrm{H}-4\right), 3.41\left(\mathrm{~s}, 3 \mathrm{H}, \mathrm{OCH}_{3}\right)$, $2.05\left(\mathrm{~s}, 3 \mathrm{H},-\mathrm{CH}_{3}\right) .{ }^{13} \mathrm{C}-\mathrm{NMR}\left(\mathrm{CDCl}_{3}, 100 \mathrm{MHz}\right) \delta(\mathrm{ppm})=$ $169.7\left(\mathrm{CH}_{3} \mathrm{C}=\mathrm{O}\right), 155.2(\mathrm{EtOC}=\mathrm{O}), 137.0,129.2,128.3,126.2$ (Ar), $101.6(\mathrm{PhCH}), 97.5$ (C-1), 79.3 (C-4), 74.9 (C-2), 68.9 (C-3, C-6), 63.4 (C-5), $55.5\left(\mathrm{OCH}_{3}\right), 55.3\left(\mathrm{OCOOCH}_{3}\right), 20.9$ $\left(-\mathrm{CH}_{3}\right)$.

\section{RESULTS AND DISCUSSION}

\section{Anionic Copolymerization of LL and MBCG}

We have reported that the cyclic carbonate MBCG could be polymerized without any decarbonylation by anionic initiators, such as 1,8-diazabicyclo[5.4.0]undec-7-ene (DBU) and potassium tert-butoxide $\left(t\right.$-BuOK). ${ }^{16}$ The alkoxide initiators also have been reported to be effective for the anionic polymerization of LL. ${ }^{23-26}$ We then used $t$-BuOK as an initiator for the copolymerization of LL with MBCG because it should be effective for both monomers. All the copolymerizations were carried out in THF at $30^{\circ} \mathrm{C}$ for $12 \mathrm{~h}$, which was determined by the each reported homopolymerization condition at $60^{\circ} \mathrm{C}$ for $12 \mathrm{~h}$ for $\mathrm{MBCG}$ and at $0{ }^{\circ} \mathrm{C}$ for $6 \mathrm{~h}$ for LL. These results are listed in Table I. The homopolymerization of MBCG in THF had been heterogeneous, ${ }^{16}$ but all the copolymerization proceeded homogeneously probably due to the enhanced solubility caused by introduction of the comonomeric LL units. The resulting methanol-insoluble products were obtained as white powders in good yields and were soluble in $\mathrm{CHCl}_{3}$, THF and DMF. The mole fractions of LL in the products $\left(f_{\mathrm{LL}}\right)$, which were estimated from the ${ }^{1} \mathrm{H}$ NMR spectra, tend to be slightly greater than those in the feeds $\left(F_{\mathrm{LL}}\right)$. SEC traces of all the products were unimodal. When the $F_{\mathrm{LL}}$ was 0.1 , the

Table I. Anionic ring-opening copolymerization of LL with MBCGa)

\begin{tabular}{rlclcc}
\hline run & $F_{\mathrm{LL}}{ }^{\mathrm{b})}$ & $\begin{array}{c}\text { Yield }^{\mathrm{c})} \\
\%\end{array}$ & $f_{\mathrm{LL}}{ }^{\mathrm{d})}$ & $\begin{array}{c}M_{\mathrm{n}}^{\mathrm{e})} \times 10^{-3} \\
\mathrm{~g} \mathrm{~mol}^{-1}\end{array}$ & $M_{\mathrm{w}} / M_{\mathrm{n}}{ }^{\mathrm{e})}$ \\
\hline 1 & 0.0 & 83 & 0 & 4.4 & 2.9 \\
2 & 0.10 & 92 & 0.16 & 5.3 & 2.6 \\
3 & 0.20 & 87 & 0.25 & 4.9 & 2.3 \\
4 & 0.30 & 82 & 0.35 & 4.8 & 2.8 \\
5 & 0.40 & 74 & 0.38 & 4.6 & 2.8 \\
6 & 0.50 & 83 & 0.48 & 5.1 & 2.4 \\
7 & 0.60 & 78 & 0.60 & 6.0 & 2.8 \\
8 & 0.70 & 81 & 0.68 & 9.8 & 2.0 \\
9 & 0.80 & 83 & 0.79 & 10.8 & 2.1 \\
10 & 0.90 & 90 & 0.89 & 10.9 & 2.6 \\
11 & 1.0 & 70 & 1.0 & 10.7 & 1.9 \\
\hline
\end{tabular}

a) Initiator, $t$-BuOK; temp., $30^{\circ} \mathrm{C}$; time, $12 \mathrm{~h}$; $[\mathrm{LL}+\mathrm{MBCG}]_{0}=$ $3.0 \mathrm{~mol} \mathrm{~L}^{-1}$; $[t-\mathrm{BuOK}]_{0}=0.12 \mathrm{~mol} \mathrm{~L}^{-1}$. b) Mole fraction of $\mathrm{LL}$ in feed. c) Methanol-insoluble part. d) Mole fraction of LL in copolymer. e) Estimated by SEC eluted with DMF using polystyrene standard. number-average molecular weight $\left(M_{\mathrm{n}}\right)$ of the polymer was 5300. The molecular weight was constant around 5000 until $F_{\mathrm{LL}}$ was 0.50 , then increased with the increasing $F_{\mathrm{LL}}$, and reached 10900 when the ratio was 0.9 .

\section{Structure of the Copolymer}

The ring-opening copolymerization, especially initiated by ionic initiators, frequently tends to produce a block copolymer or a mixture of homopolymers depending on the reactivity of the used monomers. ${ }^{27,28}$ In order to confirm the presence of copolymeric MBCG-LL linkage in the polymerization product, we prepared two model compounds, $\mathbf{3 a}$ and $\mathbf{3 b}$, and compared them to the copolymerization product based on their ${ }^{13} \mathrm{C} N M R$ spectra. The model compounds are methyl 4,6- $O$-benzylidene$\alpha$-D-glucopyranoside having an ester group at the 2-O- or 3-Oposition and a carbonate group at another position. We assumed that the ester and the carbonate groups in $\mathbf{3}$ should represent the MBCG-LL and MBCG-MBCG linkages, respectively. Scheme 2 shows the synthetic route for 3 . The preparation of $\mathbf{3}$ was started by methyl 4,6- $O$-benzylidene- $\alpha$-D-glucopyranoside (1), which was converted into mono- $O$-acetylated compounds 2 with acetyl chloride in the presence of pyridine. The 2-O-acetyl and 3-O-acetyl products ( $\mathbf{2} \mathbf{a}$ and $\mathbf{2} \mathbf{b}$, respectively) could be easily separated by column chromatography on silica gel. The acetylated position was determined by the ${ }^{1} \mathrm{H}-{ }^{1} \mathrm{H}$ and ${ }^{13} \mathrm{C}-{ }^{1} \mathrm{H}$ COSY spectra. The pure $\mathbf{2} \mathbf{a}$ and $\mathbf{2} \mathbf{b}$ were independently reacted with methyl chloroformate in the presence of pyridine to produce $\mathbf{3 a}$ and $\mathbf{3 b}$, respectively.

Figure 1 shows the ${ }^{13} \mathrm{C}$ NMR spectra of the copolymerization product (run 6) as well as the homopolymers, PLLA and poly(MBCG). Although all the peaks due to both homopolymers could be observed, some peaks, which were not found in<smiles>COC1OC2COC(c3ccccc3)OC2C(O)C1O</smiles><smiles>C1CCCCC1</smiles>

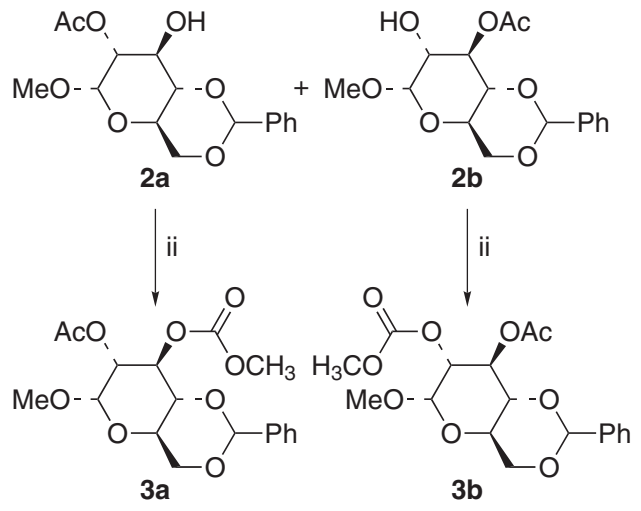

Scheme 2. Synthesis of model compounds $\mathbf{3 a}$ and $\mathbf{3 b}$. Conditions: i) $\mathbf{A c C l}$, $\mathrm{Et}_{3} \mathrm{~N}, \mathrm{THF}, \mathrm{rt}$, ii) $\mathrm{MeOCOCl}$, pyridine, THF, rt. 

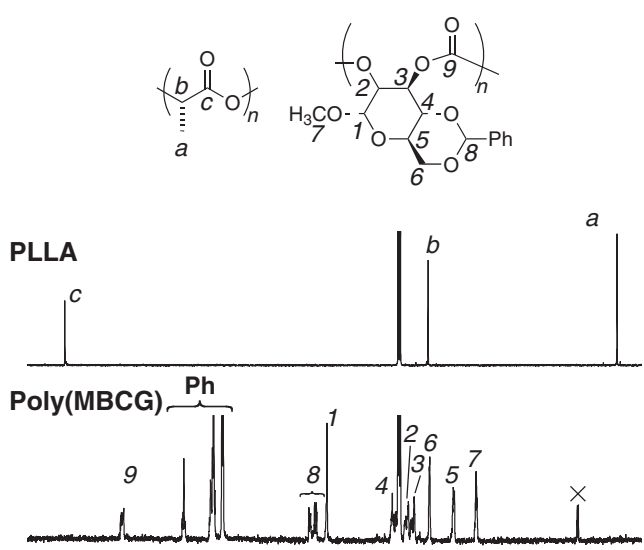

Run 6

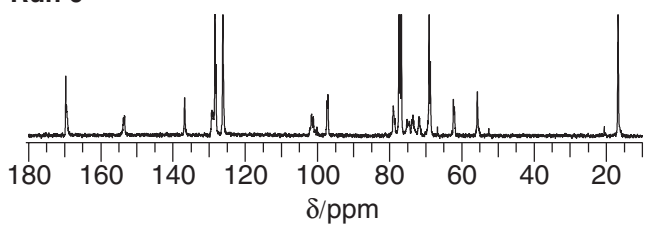

Figure 1. $100 \mathrm{MHz}{ }^{13} \mathrm{C}$ NMR spectra of PLLA, poly(MBCG) and poly(LL-coMBCG) (Run 6) measured in $\mathrm{CDCl}_{3}$ at $25^{\circ} \mathrm{C}$.

homopolymers, appeared, for example, at $72 \mathrm{ppm}$. We assumed that these peaks are due to the MBCG-LL linkage. Figure 2 shows the expanded ${ }^{13} \mathrm{C}$ NMR spectrum of the copolymerization product and the model compounds, $\mathbf{3 a}$ and $\mathbf{3 b}$. The ${ }^{13} \mathrm{C}$ NMR spectra of the model compounds indicate that the ester groups tend to shift the peaks of the attached carbon atoms to higher magnetic fields than the carbonate groups. The peak at $72 \mathrm{ppm}$ in the copolymer, which was not observed in the homopolymer, agreed with the peaks due to $\mathrm{C}-2$ of $\mathbf{3 a}$. Unfortunately, the C-3 peak of $\mathbf{3 b}$ appeared at 68 ppm was not observed in the spectrum of the polymer. This peak might overlap with the C-6 of MBCG and the methyne carbon of LL, and the presence of an ester linkage at the 3-position could not be confirmed. In addition, the C-1 peak of the copolymerization product split into $97.5 \mathrm{ppm}$ and $97.1 \mathrm{ppm}$, which correspond to that of $\mathbf{3}$ and poly(MBCG) that appeared at 97.5 and $97.1 \mathrm{ppm}$, respectively. Thus the copolymerization products contain LLMBCG linkages, and therefore the copolymerization should proceed randomly.

Finally, the copolymerization was carried out for the shorter time, in order to estimate the monomer reactivity ratio. The results are listed in Table II. The copolymerization was too fast. When $F_{\mathrm{LL}}$ was 0.51 , the copolymer yield reached to $90 \%$ for $10 \mathrm{~s}$. Shorter polymerization time such as $1-3 \mathrm{~s}$ gave lower yield (below 20\%) of the polymer. The copolymerization close to each homopolymerization (such as $F_{\mathrm{LL}}=0.12$ or 0.89 ) was too fast to suppress the copolymer yield. Using the copolymer composition at the lower polymerization yield (below 20\%), the copolymer composition curve was made as shown in Figure 3 . The monomer reactivity ratio was estimated to be $r_{\mathrm{LL}}=1.15$ and $r_{\mathrm{MBCG}}=1.47$ by Fineman-Ross method. These reactivity ratios clearly support the random copolymerization between LL and MBCG.

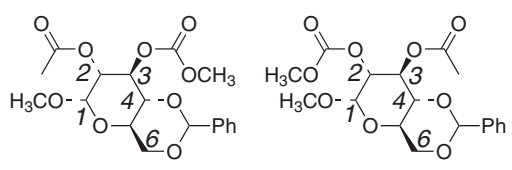

$3 a$

$3 \mathbf{b}$
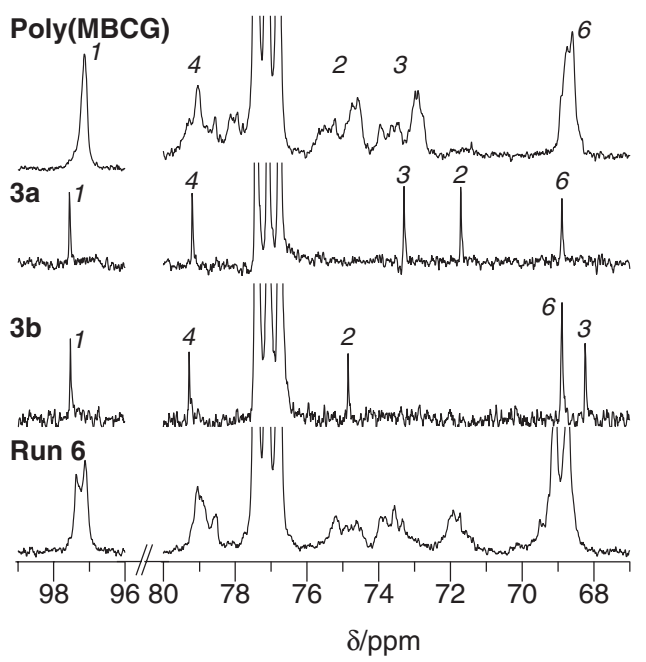

Figure 2. Expanded $100 \mathrm{MHz}{ }^{13} \mathrm{C}$ NMR spectra of poly(MBCG), model compounds $\mathbf{3 a}$ and $\mathbf{3 b}$, and poly(LL-co-MBCG) measured in $\mathrm{CDCl}_{3}$ at $25^{\circ} \mathrm{C}$.

Table II. Anionic ring-opening copolymerization of $L L$ with MBCG in short time

\begin{tabular}{|c|c|c|c|c|c|}
\hline$F_{\mathrm{LL}}{ }^{\mathrm{b})}$ & $\begin{array}{c}\text { Time } \\
\mathrm{s}\end{array}$ & $\begin{array}{l}\text { Yield }^{c)} \\
\%\end{array}$ & $f_{L L}{ }^{d)}$ & $\begin{array}{c}M_{\mathrm{n}}^{\mathrm{e})} \times 10^{-3} \\
\mathrm{~g} \mathrm{~mol}^{-1}\end{array}$ & $M_{\mathrm{w}} / M_{\mathrm{n}}{ }^{\mathrm{e})}$ \\
\hline 0.12 & 2.0 & 63 & - f) $^{-1}$ & -f) $^{\text {f }}$ & -f) $^{\text {f }}$ \\
\hline 0.20 & 2.0 & 40 & 0.16 & 6.5 & 1.6 \\
\hline 0.31 & 1.0 & 13 & 0.26 & 6.6 & 1.6 \\
\hline 0.41 & 2.0 & 11 & 0.35 & 8.3 & 1.7 \\
\hline 0.51 & 10.0 & 90 & $-^{f)}$ & -f) $^{f}$ & -f) \\
\hline 0.60 & 3.0 & 20 & 0.61 & 10.7 & 1.6 \\
\hline 0.70 & 2.0 & 5 & 0.69 & 9.7 & 1.5 \\
\hline 0.78 & 0.5 & trace & -f) $^{\mathrm{f}}$ & $-^{f)}$ & -f) \\
\hline 0.89 & 2.0 & 61 & 0.87 & 12.1 & 2.4 \\
\hline
\end{tabular}

a) Initiator, $t$-BuOK; temp., $30^{\circ} \mathrm{C}$; $[\mathrm{LL}+\mathrm{MBCG}]_{0}=3.0 \mathrm{~mol} \mathrm{~L}-1 ;[t-$ $B u O K]_{0}=0.12 \mathrm{~mol} \mathrm{~L}^{-1}$. b) Mole fraction of LL in feed. c) Methanolinsoluble part. d) Mole fraction of LL in copolymer. e) Estimated by SEC eluted with DMF using polystyrene standard. f) Not determined.

\section{Deprotection from the Copolymer}

The acetals from benzaldehyde are known as a protective group for diols, and can easily be removed under acidic or hydrogenation conditions. ${ }^{29}$ Hydroxyl groups produced by removing the benzylidene acetal of the MBCG units might give the copolymers some functionality, such as hydrophilicity, reactivity, and biofunctionality as a sugar. Thus we then examined the deprotection from the copolymers. The reaction was carried out using $90 \%$ aqueous trifluoroacetic acid in dichloromethane at $20^{\circ} \mathrm{C}$ for $1 \mathrm{~h}$. The reaction mixture was poured into diethyl ether and the precipitation was collected. Table III lists the results of the deprotection. The diethyl ether insoluble products were quantitatively obtained from all the 


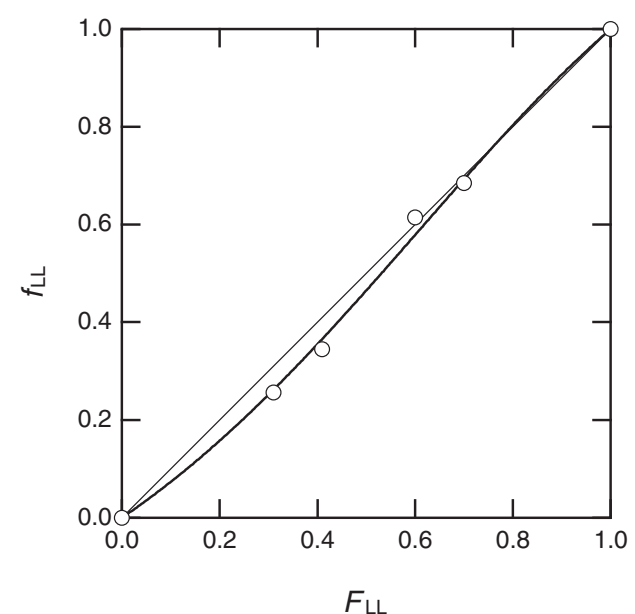

Figure 3. Plots of the mole fraction of $L L$ in copolymer $\left(f_{L L}\right)$ versus mole fraction of $\mathrm{LL}$ in feed $\left(F_{L}\right)$ for the copolymerization of $L L$ with MBCG at $30^{\circ} \mathrm{C}$ with $t$-BuOK in THF. The solid line indicates the values calculated with $r_{\mathrm{LL}}=1.33$ and $r_{\mathrm{MBCG}}=1.62$.

Table III. Deprotection of the copolymers

\begin{tabular}{cccc}
\hline$f_{\mathrm{LL}}{ }^{\mathrm{a})}$ & $\begin{array}{c}\text { Yield } \\
\%\end{array}$ & $\begin{array}{c}M_{\mathrm{n}}^{\mathrm{c})} \times 10^{-3} \\
\mathrm{~g} \mathrm{~mol}^{-1}\end{array}$ & $M_{\mathrm{w}} / M_{\mathrm{n}}{ }^{\mathrm{c})}$ \\
\hline 0.16 & $>99$ & 6.1 & 2.8 \\
0.25 & $>99$ & 8.0 & 1.7 \\
0.35 & $>99$ & 9.1 & 1.8 \\
0.38 & 93 & 6.3 & 2.1 \\
0.48 & $>99$ & 8.7 & 1.6 \\
0.60 & $>99$ & 12.2 & 1.7 \\
0.68 & $>99$ & 15.8 & 1.4 \\
0.79 & 63 & 14.6 & 1.8 \\
0.89 & 79 & 12.1 & 1.6 \\
\hline
\end{tabular}

a) Mole fraction of L-Lactide in copolymer. b) Diethyl ether-insoluble part. c) Estimated by SEC eluted with DMF using polystyrene as standard.

copolymers without any significant decrease in the molecular weight. The complete deprotection was confirmed by the ${ }^{1} \mathrm{H}$ NMR (Figure 4) and the IR (Figure 5) spectra. A broad peak due to the phenyl groups around $7 \mathrm{ppm}$ observed in the ${ }^{1} \mathrm{H}$ NMR spectrum before the deprotection completely disappeared after the deprotection. In the IR spectrum, a peak due to the carbonyl groups at $1750 \mathrm{~cm}^{-1}$ remained, and the peak due to the hydroxyl groups appeared at $3400 \mathrm{~cm}^{-1}$. These results clearly indicated that the deprotection completely proceeded to produce the copolymer having hydroxyl groups, while the polyester-carbonate main chain was not affected under the acidic conditions.

\section{Thermal Properties}

The thermal properties of the polymers were evaluated by TGA and DSC. The temperatures for a $5 \%$ weight loss $\left(T_{\mathrm{d} 5}\right)$ and the glass transition temperature $\left(T_{\mathrm{g}}\right)$ of the copolymers before and after the deprotection are listed in Table IV. The $T_{\mathrm{d} 5}$, which was $315^{\circ} \mathrm{C}$ for poly(MBCG), decreased with an increase in the $\mathrm{LL}$ content and reached $222^{\circ} \mathrm{C}$ at $f_{\mathrm{LL}}$ of 0.89 ,

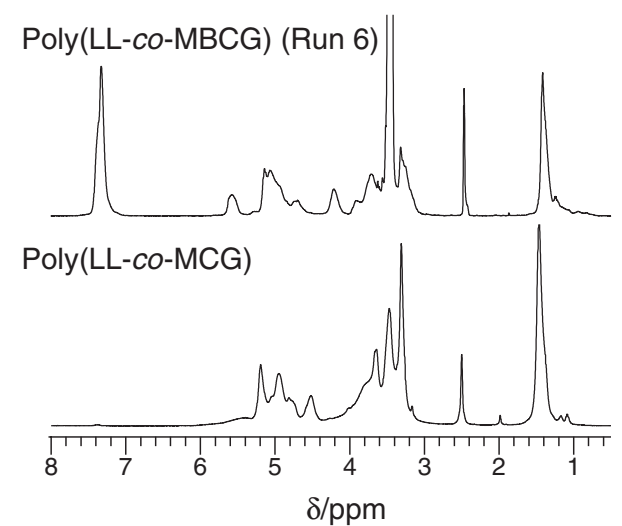

Figure 4. $400 \mathrm{MHz}{ }^{1} \mathrm{H}$ NMR spectra of poly(LL-co-MBCG) and poly(LL-co$\mathrm{MCG}$ ) measured in $\mathrm{CDCl}_{3}$ at $25^{\circ} \mathrm{C}$

Poly(LL-Co-MBCG) (Run 6)

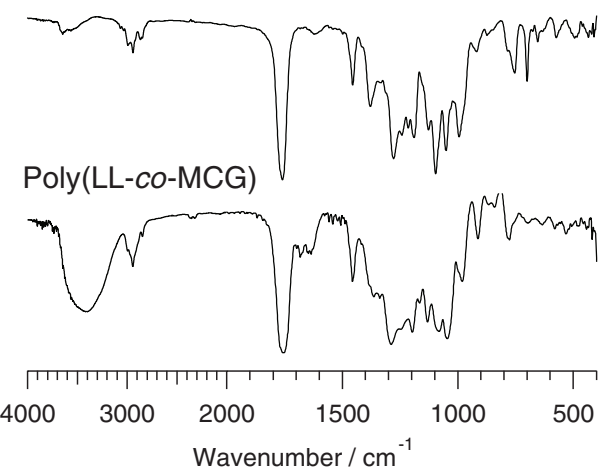

Figure 5. IR spectra of poly(LL-co-MBCG) and poly(LL-co-MCG) measured in $\mathrm{KBr}$.

Table IV. Thermal properties of the copolymers

\begin{tabular}{llllll}
\hline \multirow{2}{*}{$f_{\mathrm{LL}}$} & \multicolumn{2}{c}{ before deprotection } & & \multicolumn{2}{c}{ after deprotection } \\
\cline { 2 - 3 } \cline { 6 - 6 } \cline { 5 - 6 } & $T_{\mathrm{d} 5}{ }^{\mathrm{a})}$ & $T_{\mathrm{g}} \mathrm{b}^{2}$ & & $T_{\mathrm{d} 5}{ }^{\mathrm{a})}$ & $T_{\mathrm{g}}{ }^{\text {b) }}$ \\
\hline 0.0 & 315 & 215 & & 250 & 170 \\
0.16 & 270 & 161 & & 245 & 185 \\
0.35 & 264 & 152 & & 243 & 140 \\
0.48 & 246 & 117 & & 230 & 107 \\
0.68 & 237 & 94 & & 234 & 64 \\
0.89 & 222 & 60 & & 245 & n.d. $^{\text {c) }}$ \\
\hline
\end{tabular}

a) $5 \%$ Weight loss temperature measured by TGA. $\Delta T=10^{\circ} \mathrm{C} / \mathrm{min}$. b) Glass transition temperature recorded by DSC on the second heating scan. $\Delta T=10^{\circ} \mathrm{C} / \mathrm{min}$. c) Not determined.

whereas the $T_{\mathrm{d} 5}$ 's after the deprotection were almost constant around $240{ }^{\circ} \mathrm{C}$. In the DSC traces, all the copolymers showed only one $T_{\mathrm{g}}$ between those of poly(MBCG) $\left(215^{\circ} \mathrm{C}\right)$ and PLLA $\left(50-60^{\circ} \mathrm{C}\right)$. Figure 6 shows the DSC traces of $1: 1(\mathrm{w} / \mathrm{w})$ mixture of the corresponding homopolymers and the copolymer obtained in run 6 . The mixture shows two $T_{\mathrm{g}}$ 's corresponding to the $T_{\mathrm{g}}$ 's of the homopolymers, while the copolymer shows one $T_{\mathrm{g}}$ at $117^{\circ} \mathrm{C}$. This might support the results that the copolymerization successfully produced the random co- 


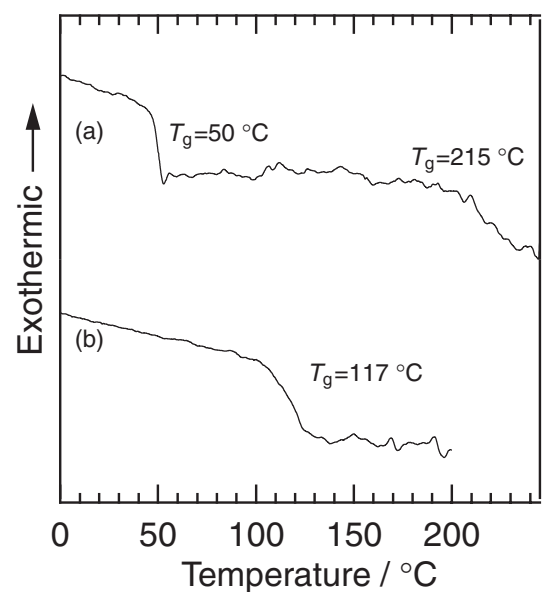

Figure 6. DSC traces of (a) $1: 1$ (w/w) mixture of PLLA and poly(MBCG), and (b) the copolymer having $f_{\mathrm{LL}}$ of 0.48 (run 6).

polymers as mentioned above. It is well known that PLLA is a crystalline polymer and melts at $160-170{ }^{\circ} \mathrm{C}$, but we could not find the melting point of the copolymers in the DSC traces below $180^{\circ} \mathrm{C}$ even for the copolymer with the $f_{\mathrm{LL}}$ of 0.89 even after a thermal treatment at $90^{\circ} \mathrm{C}$ for $2 \mathrm{~h}$. It is known that PLLA takes a left-handed $10_{7}$ helical conformation in its crystalline state. ${ }^{30}$ The bulky and rigid comonomeric MBCG units might prevent the helix formation of the PLA units.

\section{Solubility of the Copolymers}

The solubilities of the copolymers in some solvents were examined to determine any difference in the copolymers before and after the deprotection. Table IV shows the results. Before the deprotection, the copolymers were soluble in $\mathrm{CHCl}_{3}, \mathrm{THF}$, and DMF, and insoluble in water and methanol. This tendency was not affected by the difference in the $f_{\mathrm{LL}}$. After the deprotection, the copolymers became swollen in the nonpolar solvents such as $\mathrm{THF}$ and $\mathrm{CHCl}_{3}$. The hydroxyl-bearing copolymers were still insoluble in water, but swelled in methanol. Thus, the copolymer became slightly hydrophilic due to the deprotection.

\section{SUMMARY}

We carried out the anionic copolymerizations of LL with MBCG with $t$-BuOK as an initiator in $\mathrm{THF}$ at $30^{\circ} \mathrm{C}$. By comparing the structures of the copolymerization products with the model compounds $\mathbf{3}$, the copolymerizations successfully proceeded and the products possessed some MBCG-LL linkages. The copolymers were treated with trifluoroacetic acid to produce hydroxyl-bearing copolymers. During the deprotection, no significant degradation of the main chain was observed. All the copolymers did not show a melting point, and thus were amorphous. The deprotected copolymer did not dissolve in water, but was partially soluble in methanol. Thus, the hydrophilicities of the copolymer were improved by the deprotection.

\begin{tabular}{|c|c|c|c|c|c|c|}
\hline \multirow{2}{*}{ Polymer } & \multicolumn{6}{|c|}{ Solvent } \\
\hline & $\mathrm{H}_{2} \mathrm{O}$ & DMF & $\mathrm{MeOH}$ & THF & $\mathrm{CHCl}_{3}$ & $\mathrm{MePh}$ \\
\hline \multicolumn{7}{|c|}{ before deprotection } \\
\hline$f_{\mathrm{LL}}=0.0$ & - & ++ & - & ++ & ++ & + \\
\hline 0.35 & - & ++ & - & ++ & ++ & + \\
\hline 0.68 & - & ++ & - & ++ & ++ & + \\
\hline $\begin{array}{c}1.0 \\
\ldots .\end{array}$ & - & ++ & - & ++ & ++ & + \\
\hline \multicolumn{7}{|c|}{ after deprotection } \\
\hline$f_{\mathrm{LL}}=0.0$ & - & ++ & + & + & + & + \\
\hline 0.35 & - & ++ & + & + & + & + \\
\hline 0.68 & - & ++ & + & ++ & + & + \\
\hline
\end{tabular}

a) Concentration, $10 \mathrm{mg} / \mathrm{mL}$; temp., r.t. Signatures; ++: soluble, +: partially soluble or swelling, -: insoluble.

Received: December 22, 2008 Accepted: May 20, 2009

Published: July 1, 2009

\section{REFERENCES}

1. Z. G. Xie, T. C. Lu, X. S. Chen, C. H. Lu, Y. H. Zheng, and X. B. Jing, J. Appl. Polym. Sci., 105, 2271 (2007).

2. F. Li, S. M. Li, A. El Ghzaoui, H. Nouailhas, and R. X. Zhuo, Langmuir, 23, 2778 (2007).

3. Y. Lemmouchi, M. C. Perry, A. J. Amass, K. Chakraborty, and E. Schacht, J. Polym. Sci., Part A: Polym. Chem., 45, 3966 (2007).

4. C. Deng, X. S. Chen, H. J. Yu, J. Sun, T. C. Lu, and X. B. Jing, Polymer, 48, 139 (2007).

5. S. S. Venkatraman, P. Jie, F. Min, B. Y. C. Freddy, and G. LeongHuat, Int. J. Pharm., 298, 219 (2005).

6. M. Baśko and P. Kubisa, J. Polym. Sci., Part A: Polym. Chem., 45 3090 (2007).

7. F. Fay, E. Renard, V. Langlois, I. Linossier, and K. Vallee-Rehel, Eur. Polym. J., 43, 4800 (2007).

8. R. Slivniak and A. J. Domb, Biomacromolecules, 6, 1679 (2005).

9. F. Tasaka, Y. Ohya, and T. Ouchi, Macromol. Rapid Commun., 22, 820 (2001)

10. J. Helder, F. E. Kohn, S. Sato, J. W. Vandenberg, and J. Feijen, Makromol. Chem., Rapid Commun., 6, 9 (1985).

11. F. He, Y. P. Wang, G. Liu, H. L. Jia, J. Feng, and R. X. Zhuo, Polymer, 49, 1185 (2008).

12. X. L. Hu, X. S. Chen, S. Liu, Q. Shi, and X. B. Jing, J. Polym. Sci., Part A: Polym. Chem., 46, 1852 (2008).

13. X. H. Chen and R. A. Gross, Macromolecules, 32, 308 (1999).

14. R. Kumar, W. Gao, and R. A. Gross, Macromolecules, 35, 6835 (2002).

15. B. D. Mullen, C. N. Tang, and R. F. Storey, J. Polym. Sci., Part A: Polym. Chem., 41, 1978 (2003).

16. O. Haba, H. Tomizuka, and T. Endo, Macromolecules, 38, 3562 (2005).

17. K. Soga, S. Hosoda, Y. Tazuke, and S. Ikeda, J. Polym. Sci., Part A: Polym. Chem., 15, 219 (1977).

18. L. Vogdanis and W. Heitz, Makromol. Chem., Rapid Commun., 7, 543 (1986).

19. L. Vogdanis, B. Martens, H. Uchtmann, F. Hensel, and W. Heitz, Macromol. Chem. Phys., 191, 465 (1990).

20. J. C. Lee and M. H. Litt, Macromolecules, 33, 1618 (2000).

21. M. E. Evans, in "Methods in Carbohydrate Chemistry," R. L. Whistler and J. N. BeMiller, Ed., Academic Press, New York, 1980, Vol. 8, p 313.

22. W. M. Doane, B. S. Shasha, E. I. Stout, C. R. Russell, and C. E. Rist, Carbohydr. Res., 4, 445 (1967). 
23. H. R. Kricheldorf and I. Kreisersaunders, Macromol. Chem. Phys., 191, 1057 (1990).

24. Z. Jedliński, W. Walach, P. Kurcok, and G. Adamus, Macromol. Chem. Phys., 192, 2051 (1991).

25. H. R. Kricheldorf and C. Boettcher, Macromol. Chem. Phys., 194, 1665 (1993).

26. M. Bero, P. Dobrzynski, and J. Kasperczyk, J. Polym. Sci., Part A: Polym. Chem., 37, 4038 (1999).
27. M. H. Chisholm, D. Navarro-Llobet, and W. J. Simonsick, Macromolecules, 34, 8851 (2001).

28. D. Nagai, M. Nishida, B. Ochiai, K. Miyazaki, and T. Endo, J. Polym. Sci., Part A: Polym. Chem., 44, 3233 (2006).

29. P. G. M. Wuts and T. W. Greene, "Greene's Protective Groups in Organic Synthesis," 4th ed., John Wiley \& Sons, New Jersey, 2007, p 321.

30. P. De Santis and A. J. Kovacs, Biopolymers, 6, 299 (1968). 